\title{
Integration of innovative educational technologies in anatomy teaching: new normal in anatomy education
}

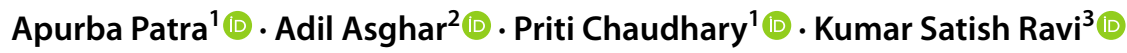

Received: 12 November 2021 / Accepted: 29 November 2021 / Published online: 8 January 2022

(c) The Author(s), under exclusive licence to Springer-Verlag France SAS, part of Springer Nature 2021

\begin{abstract}
COVID-19 pandemic has created a lot of turmoil in medical teaching, the magnitude of impact is many folds in the subject of anatomy, as it is practical based. A major challenge for anatomy teachers is to replicate the experience of practical exposures. These exposures range from cadaveric dissection to demonstration of bones, museum specimens, and histology slides, where they will have interactive communication with students, and thus help in the enhancement of communication and clinical skills among them. In recent days, anatomy teachers throughout the globe started using various advanced technology to make the teaching-learning session more interesting. In pre-pandemic era, usage of such advancements in information and communication technology was a 'choice'. But pandemic has changed the situation drastically, what was a 'choice' earlier is now an 'obligation.' Presently although infection rate is low, vaccination rate is high, most of the medical schools re-opened for usual offline teaching, still body donation is all time low making the situation 'back to square one'. Keeping such unprecedented situations in mind, we need to incorporate various innovative educational technologies in day-to-day teaching-learning methodologies.
\end{abstract}

Keywords Dissection $\cdot$ Educational technics $\cdot$ Manikins $\cdot$ Pedagogy $\cdot$ Teaching method $\cdot$ Virtual reality

\section{Introduction}

Anatomy teaching or Anatomy education that merely started with blackboard method has evolved through overhead projector, PowerPoint presentation, 3D models, virtual dissector and now online remote learning using 3D virtual dissection. Human Anatomy as a subject lays the foundation of medicine, understanding the complexities of a human body

Apurba Patra

apurba.cnmc03@gmail.com

Adil Asghar

dradilasghar@aiimspatna.org

Priti Chaudhary

anataiimsbti@gmail.com

Kumar Satish Ravi

drksravi.jipmer@gmail.com

1 Department of Anatomy, All India Institute of Medical Sciences, Bathinda, India

2 Department of Anatomy, All India Institute of Medical Sciences, Patna, India

3 Department of Anatomy, All India Institute of Medical Sciences, Rishikesh, India is prerequisite in becoming a competent clinician and the onus is on the Anatomy teachers to do the job [34]. Modern teachers not only teach their students but also facilitate the learning process among them using various innovative technologies. Induction of such newer educational technologies is not altogether new; these modalities are already in use, but their importance has been increased exponentially in the current scenario. So, anatomy teachers need to keep themselves updated with advanced technologies in medical education. Meanwhile, the learning habits of students have also evolved drastically, they no longer rely on textbooks for acquiring knowledge. They are quite tech savvy and well adjusted with all types of technologies in learning anatomy. They are now using YouTube videos, various learning apps and attending online workshop to update their dissection skills [31]. Anatomy studio, virtual dissector, simulation labs, radiology machine, etc. are new additions to learn anatomy. Endoscopic anatomy is the latest evolving trend that teaches the students beyond anatomical positions and gives a whole new perspective to the body [36]. Keeping such newer trends in mind, we have put forward various educational technologies and their role in instructional delivery of anatomy in post COVID era. 


\section{Advanced educational technologies for teaching anatomy}

\section{Web-based learning}

Anatomy education passing through a paradigm shift, online web-based remote learning, and portable network devices are becoming a fundamental component of the learning environment in anatomy education, having an impact on design, and re-shaping the anatomy curriculum. In today's scenario, a vast wealth of web-based information in the form automated learning system or interactive programs is available at the student's fingertips which can be used as a source of self-directed learning. Nowadays, everything is available online, starting from lecture schedule, ready to see presentations, examination schedule, results of assessment everything by one click [27]. Courses are predominantly delivered online via zoom meetings, google classroom, Microsoft teams, etc. Although, formal lectures are still predominantly used for anatomy education, these new communication and information technologies can enhance the teaching and learning environment. They have the capacity to facilitate better integration between learning and problem-solving approach, as they impart large amounts of factual information in an organized fashion in digitalized form to make conventional didactic lectures more interesting. Although webbased platforms are popular among students, they need to be vigilant. Wikipedia, a popular online encyclopedia providing imperfect, inaccurate and missing information [24]. Furthermore, a considerable proportion of references cited in entries are from poorly identified sources. While Wikipedia is an easily accessible resource for many people and much of the anatomic information is appropriate, it cannot be considered an equivalent resource compared to anatomic texts.

\section{Computer-based educational programs and technology}

Computer-based educational programs are already in use to facilitate the transition from the predominantly didactic mode of delivery to the predominantly virtual one. For example, the Complete 3D Anatomy educational program by Elsevier was used for the teaching of functional Anatomy during pandemic successfully. The voice recording features allow us to create videos by merging the dynamic $3 \mathrm{D}$ representations and creations. Such video lectures can be linked to the learning management system (LMS) or shared with a group of learners directly through the programs platform [31]. Additionally, it offers the kinesthetic advantage of learning based on the visual, auditory, reading/writing, and kinesthetic (VARK) theory [4, 28, 30].

\section{Virtual classroom}

Current techniques such as smart boards for making diagrams, hyperlink video presentation (Osmosis videos [14, 15] and ScholarRx videos [23]) through LMS, 3D images are more fascinating for students and making them active learners. Nowadays, Anatomy lectures are no more passive learning, rather more engaging. Class schedule, teacher's presentations, and assessment results are available online now. Courses are predominantly delivered online via LMS or a Virtual Learning Environment (VLE) [27]. The LMS can potentially trail learners' activities, progress, and compliance with course assignments. It can also facilitate peer to peer and teacher to student communication. Presently, many medical schools provide their students with lecture broadcast, allowing them to attend the 'virtual classroom' anywhere and anytime [31]. With such information technologies, anatomy 'goes beyond' lecture theaters and dissection halls. These are even more pertinent in completing the anatomy curriculum in the current pandemic situation. With due course of time, learning habits of students have changed too, instead of classical textbooks, now they use e-books on smart phones, laptops or tablets. These are easy to access 'moving libraries', allowing them to consult one even in mid of the lecture.

\section{Anatomy Studio}

Anatomy Studio, is a collaborative Mixed Reality (MR) tool for virtual dissection through augmented three-dimensional reconstruction (3DR) (Fig. 1). It combines sketching on a tablet with MR-based visualization to perform 3DR of anatomic structures through contour drawing on 2D images of real cross sections (i.e., cryosections) [41]. While the tablet's interactive surface offers a natural sketching experience, the $3 \mathrm{D}$ visualization provides an improved perception of the resulting reconstructed content over traditional desktop approaches. It is also possible to interact with Anatomy Studio using mid-air gestures in the MR visualization to browse the slices. In addition, Anatomy Studio enables two or more experts to collaborate, showing in real time the modifications made to the contours by each other, and easing communication. Thus, it helps students and surgeons in surgical skill training. Momentarily, when there is global shortage of cadavers, anatomists and students can rely on a wide variety tool for 3D reconstruction from anatomical slices (3DRAS). These tools suit several purposes: promote novel educational methods [32, 40], allow statistical analysis of anatomical variability [37], and support clinical practice to optimize decisions [26]. 
Fig. 1 Overview of Anatomy Studio, a collaborative Mixed Reality (MR) tool for virtual dissection through augmented three-dimensional reconstruction (3DR) [41]. (Permitted to re-use under license no: 5191741337120 dated 18 Nov 2021@ 2019 Elsevier)

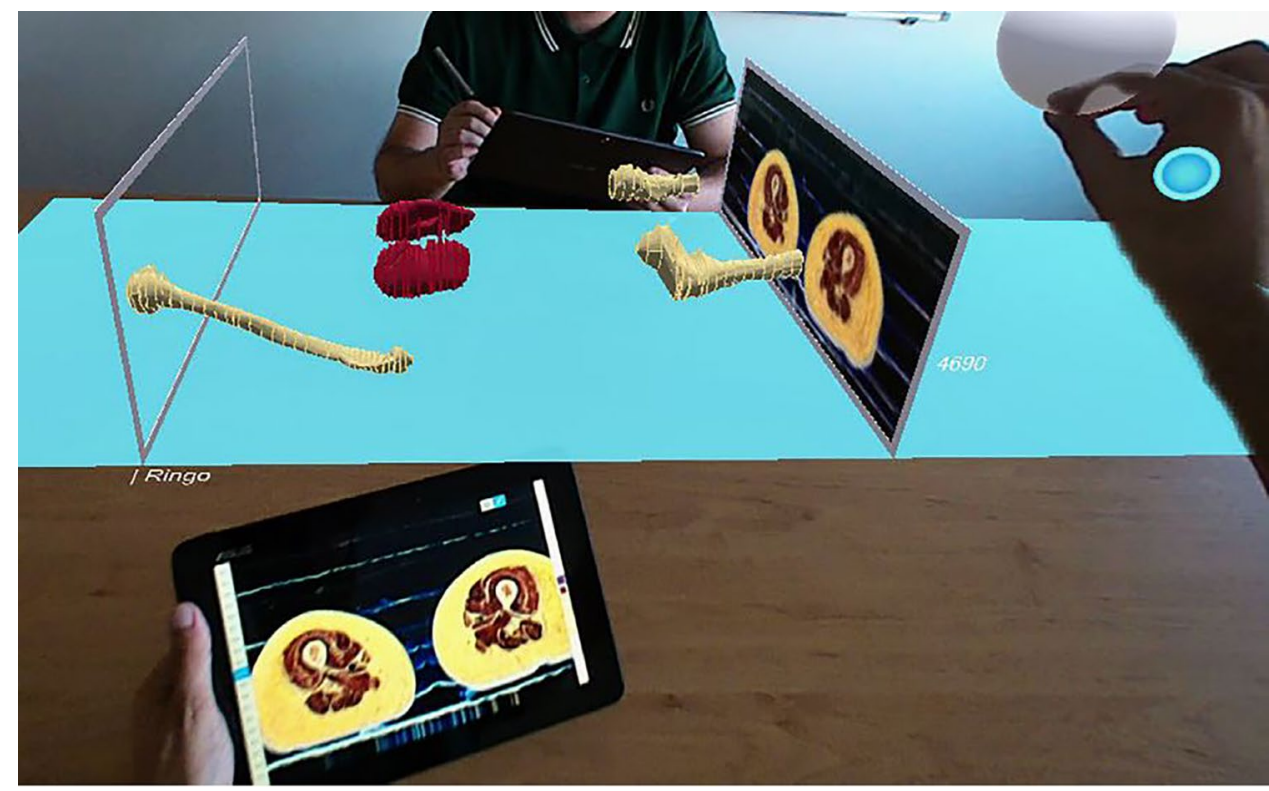

\section{Artificial intelligence/humanoid robots}

Anthony Seldon claimed boldly at British Science Festival that Robots will replace teachers by 2027. A robot can take over few desk jobs and are regularly used in hospitals during COVID-19 pandemic in China. These artificially intelligent humanoid robots are already replacing finance and advertising experts, clerical staff, or even nursing care providers. So, as a teacher of anatomy, the question comes into our mind is the scope of such robot in teaching anatomy? As a subject, it holds a crucial position in the medical training, so vigorous teaching is cardinal to make the undergraduates understand about the anatomy of the diseases [38].

An anatomy teacher needs the qualities of construction and instantiation of anatomical concepts and their expression. Teachers should clarify the semantic relationship between anatomical structure, histological structures and physiological functions [17]. Teachers facilitate the evolutionary or clinical integration of different anatomical information and maintain physiological function integrity and conceptual model. Scientists have gone further technological leap toward developing a robot with a skeleton and muscular system that is nearly identical to that of a human being. Learner has widespread academic and psychological needs, such as empathy, grit and co-operation. So, it will be difficult for robot or artificial intelligence to provide such requirements. Moreover, educating these adult learners who study with their own pace and spirit and have different mental setup or emotional levels is a concern. The robot, named Aldebaran NAO V5, conducts the Mapping humanoid walking onto a reinforcement learning task (Fig. 2) [11].

\section{Cloud technology}

Cloud technology is already in use to store and share digital textbooks, lessons, videos, assignments and even facility of live chat. This technology enables us to formulate a new educational model known as flipped classrooms. In this technique, students attend a lecture prior to the class and discuss the topic during the class. Group work and analytical activities can be taken up in the classroom setting. Flipped classroom has improved the learning outcomes, not just in terms of student performance as measured through assessment but also in terms of competency and internalization of information with the benefit of facilitating continuing learning better $[18,20]$.

\section{D stereoscopy}

Stereoscopic 3D instructional videos are now easily accessible via smartphone and affordable for students. The use of this kind of stereoscopic 3D video in their normal teaching as a complementary tool has been proven advantageous over $2 \mathrm{D}$ videos. The incorporation of $3 \mathrm{D}$ videos as ancillary teaching into curricula could be of interest to improve the knowledge of anatomical relationships and reasoning among students [3]. To be more specific, stereoscopic 3D visualization is particularly helpful in providing a clear, simple, and accurate message about the complex three-dimensional (3D) architecture of the brain. The stereoscopic 3D teaching of neuroanatomy made medical students enthusiastic involving digital technologies. It could improve their anatomical knowledge and test scores, as well as their clinical competences. Depending on university means and the commitment 

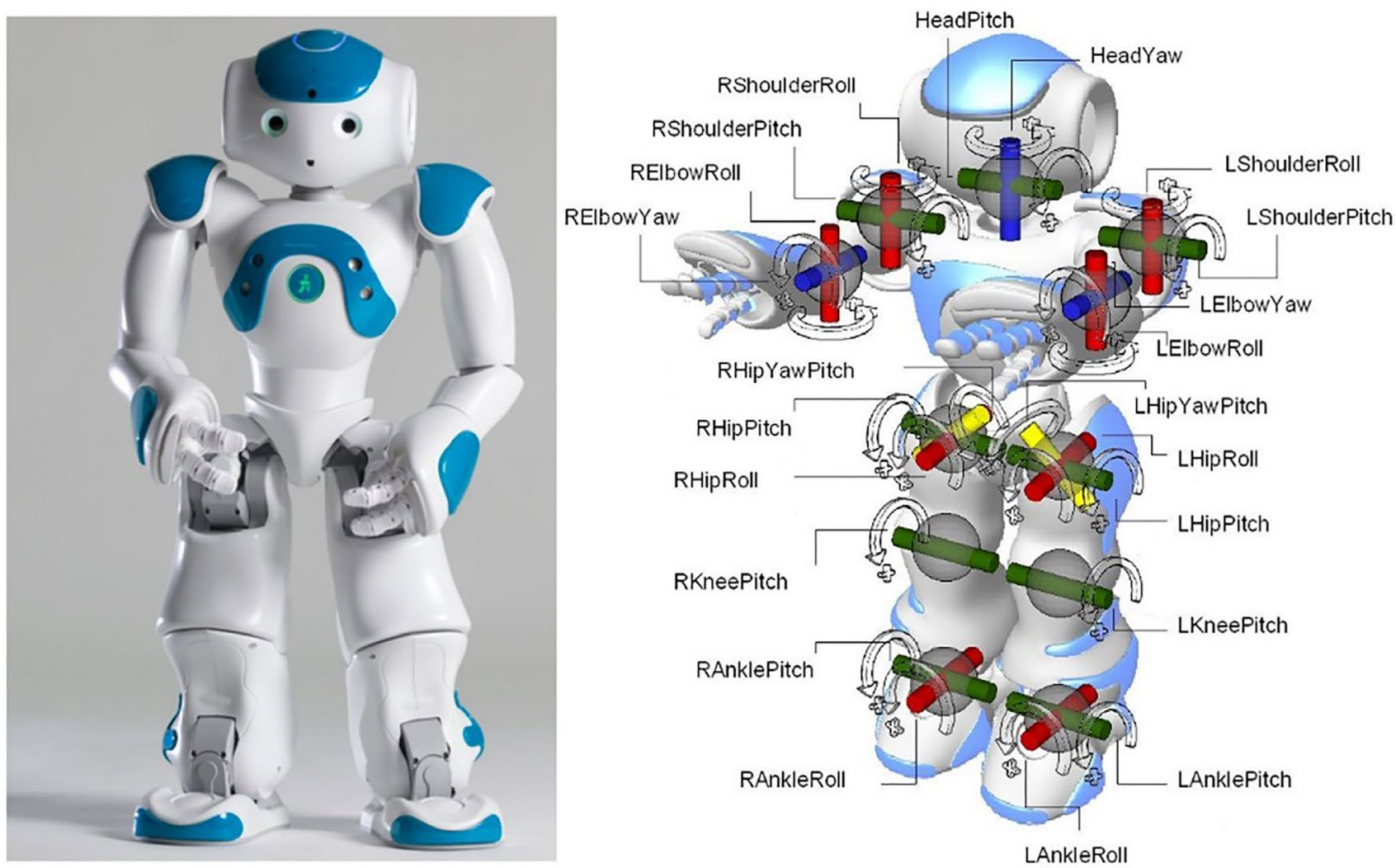

Fig. 2 The robot, named Aldebaran NAO V5 robot to conduct the Mapping humanoid walking onto a reinforcement learning task [11]. (Permitted to re-use under license no: 5194110132450 dated 22 Nov 2021@ 2019 Elsevier)

of teachers, this new tool should be extended to other anatomical fields [21].

\section{Virtual dissection}

The perspective of the Anatomy educators toward dissection has evolved according to the certain societal and professional demands of their time [13]. Over the last decades, anatomy education is gradually drifting from cadaveric dissection to virtual dissection, pre-dissected plasticized specimens and virtual 3D body systems. Previously, only resourceful medical schools were using virtual dissector, but now it becomes a trend. Virtual dissection table uses simulation technology to provide realistic visualization of 3D anatomical details of virtual cadaver. Unlike cadavers, the students can do-undo-redo the dissection repeatedly. Currently, when most medical schools do not have access to the human body due to COVID-19, virtual dissector is of real help to complete the curriculum. Such a virtual dissector contains images of gross and regional anatomy created by digitally tracing real non-chemically treated cadavers. Image library includes a variety of microscopic histology scans which students can examine microscopic tissue structures and cell-specific biomarkers from a collection of accurately stained digital scans [10].

\section{High-fidelity simulation}

High-fidelity simulation is an educational technology and pedagogy that uses sophisticated manikins in simulated patient environments, also known as a human patient simulator (Fig. 3). This method uses computerized systems to control full-body manikins, programmed to give realistic responses to learners' actions. As such, these manikins can demonstrate physiological and pathophysiological processes normally and respond to interventions, making them highly useful to teach complex phenomena. The manikins are capable of replicating all the vital signs and features, allowing us to better present structures, functions, symptoms, and medical skills to learners [20]. Although technology-based simulations are the latest trend in anatomy education, the roles of low cost, low fidelity model as a teaching and learning assistant can not be overlooked [19]. 


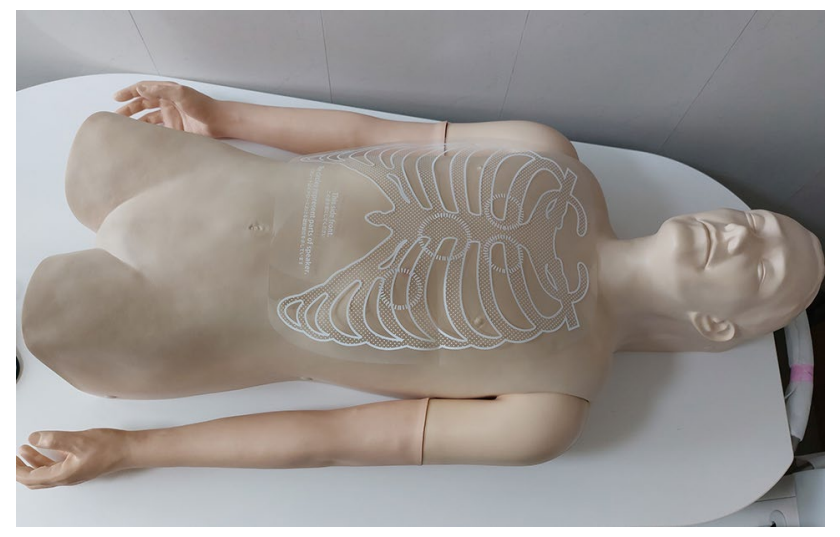

Fig. 3 High-fidelity simulation with sophisticated manikins in simulated patient environments, also known as a human patient simulator

\section{Imaging modalities}

Such as plain radiographs, computed tomography (CT) and magnetic resonance imaging (MRI) are intensively utilized in most of the anatomy courses for better understandings of various clinical conditions discussed in gross anatomy sessions [27]. Nowadays, many institutions have ultrasound facility with probe to better learnings. Recently, medical technologies are providing synthetic cadavers, organs fitted inside with ultrasound probe for better visualization. In addition, use of endoscopy and colonoscopy to visualize the internal anatomy of the gut can potentially make the topic interesting and students more engaging.

\section{Immersion or haptic technology}

Virtual reality (VR), augmented reality (AR), and other innovative technologies present a unique scenario. An alternate reality has a range of strategies for teaching health professional of all ages. Learners at all levels can benefit from computer-generated simulations. The human-computer interface (HCI) is used to construct virtual environments for students to engage with and experience. It varies in terms of immersion, fidelity, and interactivity. Immersive, high-definition visual inputs generate accurate digital representations of the actual world in virtual reality. Head mounted displays (VR headsets), motion sensors, controllers, keyboards, and speech recognition software are used to interact with the virtual world. In contrast, AR overlays computer-generated stimuli on real-world environments or objects, such as computer-generated anatomical structures overlaid on a manikin [22]. Alternate reality platforms provide an alternate world where users can engage with and affect a storyline by making choices. Participants interact with virtual worlds using real-world technology in alternate reality simulations, such as interfacing with patient data in electronic health record simulations. Although the forms exist on an overlapping continuum often characterized as "mixed reality," the degree of immersion into the virtual world is what essentially distinguishes VR from AR and alternate reality. Pictorial presentation of virtual augmented and alternate reality showing their optimal use in education [22] (Creative Commons Attribution Non-Commercial No Derivatives License 4.0) (Fig. 4).

\section{D printing}

3D printing (3DP) technology which include scanning and printing of anatomical structures of dissected specimens is another newer modality to make students learn better. It is an impressive application of creating organs and models that students can investigate to have interaction and learn in a group [36]. 3DP, particularly those not easily visible on cadavers and difficult to visualize (bones of the middle ear, cavities such as sinuses and ventricles of the brain) can be used in clinical anatomy training [1]. Although, 3DP is significantly superior to two-dimensional images in terms of the investigated parameters. However, comparison between 3DP and cadavers' dissection by students did not take place in any study. The 3DP implementation in anatomy education showed promising outcomes. However, the lack of studies which compared the educational effectiveness of 3DP with that of cadavers' dissection is highlighted. It seems that 3DP could certainly be used as an adjunct to cadavers' dissection. Further research could clarify if 3DP could obtain a more prominent role in anatomy pedagogy compared to other anatomy teaching modalities [7]

\section{Social media}

Furthermore, social media platforms, such as Facebook, Instagram, Twitter and other applications allow students to connect and schedule tutorial sessions, group study sessions and facilitate the sharing of information and peer-to-peer learning. Such platforms do not necessarily enhance students' learning ability but facilitate communication, relieve anxieties, raise morale, and help create and provide a support network during a difficult module [16].

\section{Simulation-based assessment or evaluation}

Pandemic shattered the usual pedagogy of anatomy education. Although faculty and students managed to adapt with the online teaching-learning methodology, the assessment part remained an unresolved dilemma. Online assessment is a huge task, most of the faculty and students are struggling to get the appropriate one [2,9]. Summative assessments are the prime modalities to evaluate the trainee's performance at the end of the semester or year. The concept of 
Fig. 4 Figure: Graphic representation of virtual reality, augmented reality, and alternate reality, including optimal educational applications [17]. (Permitted under Creative Commons Attribution Non-Commercial No Derivatives License 4.0)

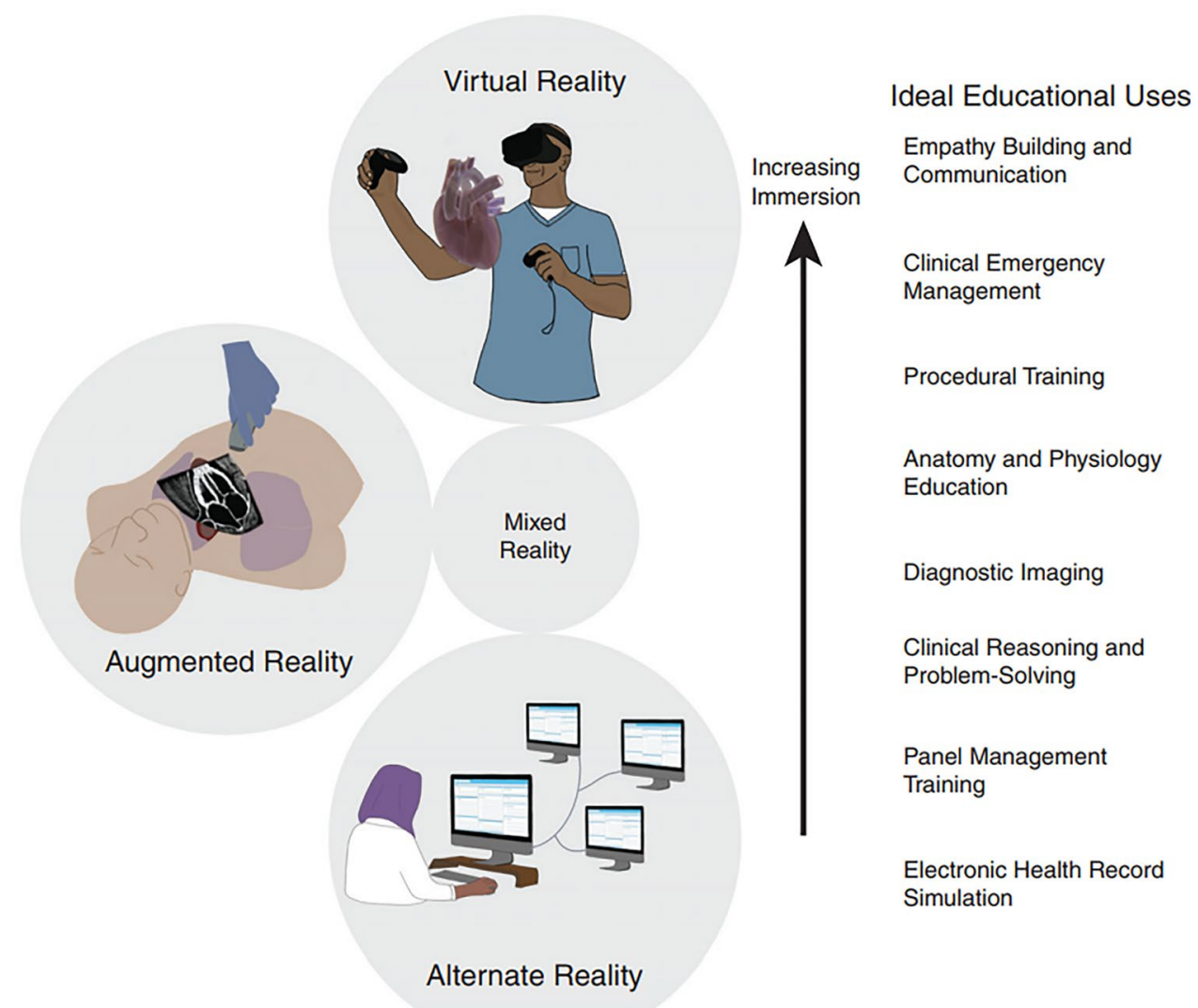

virtual patient/cadaver is altogether a new and innovative concept that can be undertaken in the present scenario, although needs further enhancement to be considered a regular method of assessment. Multiple choice questions, short answer questions are appropriate and time-tested tools in evaluating knowledge, concept, synthesis and analysis, whereas observed Structured Clinical Examinations (OSCEs) or viva voce helps to assess clinical skills of the learner through simulation-based interactions. Imperial college and King's college have successfully conducted the first ever online open book assessment (OBE) as a part of their novel summative assessment strategies [5, 39]. Similarly, US National Board of Medical Examiners (NBME) have designed virtual invigilators to conduct fair and legitimize medical assessments [29]. New Zealand used diverse platforms/policies for online assessments (random Q\&A, modified weighting, pass/fail, and team exams) [33].

\section{Further thoughts and recommendations}

Undoubtedly, the teaching of Anatomy and related basic medical sciences could be improved with strategic adaptations, and the use of technology and media [23]. The COVID-19 pandemic has simply provided reflections and insight into the pros and cons of technology and innovation as well as their creative uses. Certainly, the continual integration of technology into Anatomy education is crucial to improving learning outcomes and addressing the cognitive load associated with the volume of anatomy education and training [12]. Certain traditional pedagogical practice, such as cadaveric dissection is almost synonymous with the teaching of Anatomy. However, if the pandemic last for several months or years, it would be impractical to imagine the shutdown of anatomy education with limited number of cadavers. Hence, technology remains a dependable means to guarantee that students do not have to bear the deficits resulted by the inability to adapt and embrace available benefits that technology might offer. Therefore, the judicial use of technology and creative adaptations is the need of the hour to ensure timely, effective and impactful delivery of Anatomy education despite the constraints evolved during or even after the pandemic $[25,35]$.

\section{Limitations}

It is important to state that despite the huge benefits offered by the adoption of technology and the adaptations that enabled continuous teaching with optimal results during the 
COVID-19 lockdown as discussed, there were a number of limitations that we identified.

1. Cadaveric dissection gives students a real-time learning experience and helps them develop surgical skills at a very early stage, whereas virtual cadavers provide realistic visualization of 3D anatomical details. Learning anatomy with virtual dissection is unrealistic. The feel of touching the cadaver, incise the skin, and looking into the natural complexities of the body cannot be simulated perfectly. So, these newer technologies can be used as an add on to visualize the anatomy of complex structures, such as middle ear cavity or ethmoidal air sinuses for the improvement of fine motor skills in a stress-free environment.

2. Although, Cadaveric simulation have been proven to be useful in content delivery but to improve surgical skills among post graduate trainees practicing on cadavers is unparalleled.

3. Cost (buying and maintenance) associated with all these newer modalities is too high, not all medical schools can afford.

4. Most of the faculty are not well accustomed to these newer educational tools, thus pedagogic training for faculty is strongly recommended across the globe [6]

5. Inequality of access to online technology: Despite many online modalities or software programs available for students to use, they can often be expensive. Not every student can afford or has exclusive access to a device suitable for remote learning. In country like India, where most of the students belong to rural and suburban, the nonavailability of reliable Internet connection makes the situation worse.

6. Performance anxiety due to lack of confidence: Anatomy education simply providing an online atlas is unlikely to give students an appreciation for the fabric of the human body. While these might not absolutely stop teaching and learning activities, it would become important specifically to address them to specifically address their implications and mitigate their effects.

\section{Conclusory statements/take home message}

Momentarily, it is quite impractical to reach a global consensus regarding what is best for students and communities in post COVID era. Meanwhile, each country needs to formulate their own regime to continue with high standard anatomy teaching and training. It may solicit time span, prioritization and empathy to re structure the anatomy education without disfiguring its original fabric. The unprecedented use of online pedagogy (pre-recorded lectures, medical simulations, virtual cadavers) has been proved to be effective as an interim solution in completing ongoing course content and lectures, the long-term outcomes might remain equivocal. Policy makers need to think critically on how to amalgamate the offline and online modalities to timely reform anatomy education. Last but not the least, as said by Estai and Bunt [8] "The best way to teach modern anatomy is by combining multiple pedagogical resources to complement one another. Students appear to learn more effectively when multimodal and system-based approaches are integrated."

Author contributions AP and AA: project development, manuscript writing; PC: manuscript editing; KSR: manuscript editing critical revision. Approval of the final version of the manuscript: all authors.

Funding Non funded.

\section{Declarations}

Conflict of interest The authors declare that they have no conflict of interest.

\section{References}

1. AbouHashem Y, Dayal M, Savanah S, Štrkalj G (2015) The application of 3D printing in anatomy education. Med Educ Online 20:29847. https://doi.org/10.3402/meo.v20.29847

2. Bao W (2020) COVID -19 and online teaching in higher education: a case study of Peking University. Human Behav Emerg Tech 2:113-115. https://doi.org/10.1002/hbe2.191

3. Bernard F, Richard P, Kahn A, Fournier HD (2020) Does 3D stereoscopy support anatomical education? Surg Radiol Anat 42:843-852. https://doi.org/10.1007/s00276-020-02465-z

4. Bhagat A, Vyas R, Singh T (2015) Student's awareness of learning styles and their perceptions to a mixed method approach for learning. Int J App Basic Med Res 5:58. https://doi.org/10.4103/ 2229-516X.162281

5. Birch E, de Wolf M (2020) A novel approach to medical school examinations during the COVID-19 pandemic. Med Educ Online 25:1785680. https://doi.org/10.1080/10872981.2020.1785680

6. Chia T (2020) Anatomy teaching by only medically qualified faculty is infeasible. Surg Radiol Anat 42:857. https://doi.org/10. 1007/s00276-020-02454-2

7. Chytas D, Johnson EO, Piagkou M, Tsakotos G, Babis GC, Nikolaou VS, Markatos K, Natsis K (2020) Three-dimensional printing in anatomy teaching: current evidence. Surg Radiol Anat 42:835-841. https://doi.org/10.1007/s00276-020-02470-2

8. Estai M, Bunt S (2016) Best teaching practices in anatomy education: a critical review. Ann Anat 208:151-157. https://doi.org/10. 1016/j.aanat.2016.02.010

9. Fernandez AA, Shaw GP (2020) Academic leadership in a time of crisis: the coronavirus and COVID-19. J Ldrship Stud 14:39-45. https://doi.org/10.1002/jls.21684

10. García Martín J, Mora D, Aguado-Henche S (2019) Possibilities for the use of anatomage (the anatomical real body-size table) for teaching and learning anatomy with the students mini review open access. Biomed Sci Technol 4:4080-4083. https://doi.org/ 10.26717/BJSTR.2018.04.001094 
11. García J, Shafie D (2020) Teaching a humanoid robot to walk faster through Safe Reinforcement Learning. Eng Appl Artif Intell. https://doi.org/10.1016/j.engappai.2019.103360

12. Gaur U, Majumder MAA, Sa B, Sarkar S, Williams A, Singh K (2020) Challenges and opportunities of preclinical medical education: COVID-19 crisis and beyond. SN Compr Clin Med 2:1992-1997. https://doi.org/10.1007/s42399-020-00528-1

13. Gregory SR, Cole TR (2002) The changing role of dissection in medical education. JAMA 287:1180. https://doi.org/10.1001/ jama.287.9.1180-JMS0306-4-1

14. Guven T, Geraci C, Green J, Neist J, Gopalakrishnan M, Bhatt P, Cupino T, Azzam A (2020) Learning through Osmosis: a global Wikipedia editing course for medical students. MedEdPublish 9:1-8. https://doi.org/10.15694/mep.2020.000109.1

15. Haynes MR, Gaglani SM, Wilcox MV, Mitchell T, DeLeon V, Goldberg H (2014) Learning through Osmosis: a collaborative platform for medical education. Innov Glob Med Health Educ 2:1-8. https://doi.org/10.5339/igmhe.2014.2

16. Hennessy CM, Kirkpatrick E, Smith CF, Border S (2016) Social media and anatomy education: using twitter to enhance the student learning experience in anatomy. Anat Sci Educ 9:505-515. https:// doi.org/10.1002/ase. 1610

17. Hermiz DJ, O'Sullivan DJ, Lujan HL, DiCarlo SE (2011) Constructivist learning of anatomy: gaining knowledge by creating anatomical casts. Anat Sci Educ 4(2):98-104. https://doi.org/10. 1002/ase. 206

18. Hew KF, Lo CK (2018) Flipped classroom improves student learning in health professions education: a meta-analysis. BMC Med Educ 18:38. https://doi.org/10.1186/s12909-018-1144-z

19. Hindmarch J, Bazzi K, Lahoud J, Malik A, Sinha S (2020) Evaluating a low-fidelity inguinal canal model. Surg Radiol Anat 42:1323-1328. https://doi.org/10.1007/s00276-020-02553-0

20. Hurtubise L, Hall E, Sheridan L et al (2015) The flipped classroom in medical education: engaging students to build competency. J Med Educ Curric 2:35-43. https://doi.org/10.4137/ JMECD.S23895

21. Jacquesson T, Simon E, Dauleac C, Margueron L, Robinson P, Mertens P (2020) Stereoscopic three-dimensional visualization: interest for neuroanatomy teaching in medical school. Surg Radiol Anat 42:719-727. https://doi.org/10.1007/s00276-020-02442-6 (Epub 2020 Feb 29 PMID: 32114650)

22. Kassutto SM, Baston C, Clancy C (2021) Virtual, augmented, and alternate reality in medical education: socially distanced but fully immersed. ATS Scholar. https://doi.org/10.34197/ATS-SCHOL AR.2021-0002RE

23. Le TT, Prober CG (2018) A proposal for a shared medical school curricular ecosystem. Acad Med 93:1125-1128. https://doi.org/ 10.1097/ACM.0000000000002194

24. London DA, Andelman SM, Christiano AV, Kim JH, Hausman MR, Kim JM (2019) Is Wikipedia a complete and accurate source for musculoskeletal anatomy? Surg Radiol Anat 41:1187-1192. https://doi.org/10.34197/ATS-SCHOLAR.2021-0002RE10.1007/ s00276-019-02280-1

25. Longhurst GJ, Stone DM, Dulohery K, Scully D, Campbell T, Smith CF (2020) Strength, weakness, opportunity, threat (SWOT) analysis of the adaptations to anatomical education in the United Kingdom and Republic of Ireland in response to the Covid-19 pandemic. Anat Sci Educ 13:301-311. https://doi.org/10.1002/ ase. 1967

26. Malmberg F, NordenskjÃld R, Strand R, Kullberg J (2017) Smartpaint: a tool for interactive segmentation of medical volume images. Comput Methods Biomech Biomed Eng Imaging Vis 5:36-44. https://doi.org/10.1080/21681163.2014.960535
27. Mavrych V (2016) Modern trends in clinical anatomy teaching. MOJ Anat Physiol 2:1-2. https://doi.org/10.15406/mojap.2016. 02.00035

28. Mozaffari HR, Janatolmakan M, Sharifi R, Ghandinejad F, Andayeshgar B, Khatony A (2020) The relationship between the VARK learning styles and academic achievement in dental students. Adv Med Educ Pract 11:15-19. https://doi.org/10.2147/ AMEP.S235002

29. NBME (2021) Coronavirus (COVID-19): Assessment Information and Updates I NBME. [cited 2021 Nov 11]. Available at: https:// www.nbme.org/news/coronavirus-covid-19-assessment-infor mation-and-updates

30. Othman N, Amiruddin MH (2010) Different perspectives of learning styles from VARK model. Proc Soc Behav Sci 7:652-660. https://doi.org/10.1016/j.sbspro.2010.10.088

31. Owolabi J, Bekele A (2021) Implementation of innovative educational technologies in teaching of anatomy and basic medical sciences during the COVID-19 pandemic in a developing country: the COVID-19 silver lining? Adv Med Educ Pract 12:619-625. https://doi.org/10.2147/AMEP.S295239

32. Papa V, Vaccarezza M (2013) Teaching anatomy in the XXI century: new aspects and pitfalls. Sci World J 2013:310348. https:// doi.org/10.1155/2013/310348

33. Pather N, Blyth P, Chapman JA et al (2020) Forced disruption of anatomy education in Australia and New Zealand: an acute response to the Covid-19 pandemic. Anat Sci Educ 13:284-300. https://doi.org/10.1002/ase.1968

34. Patra A, Chaudhary P, Ravi KS (2020) Adverse impact of Covid19 on anatomical sciences teachers of India and proposed ways to handle this predicament. Anat Sci Educ 14:163-165. https://doi. org/10.1002/ase.2052

35. Saverino D (2021) Teaching anatomy at the time of COVID-19. Clin Anat 34:1128-1128. https://doi.org/10.1002/ca.23616

36. Sharma A, Kumar A (2021) Evolving trends in anatomy-a global perspective. Indian J Clin Anat Physiol 8:159-161. https://doi.org/ 10.18231/j.ijcap.2021.037

37. Shepherd T, Prince SJD, Alexander DC (2012) Interactive lesion segmentation with shape priors from offline and online learning. IEEE Trans Med Imaging 31(9):1698-1712. https://doi.org/10. 1109/TMI.2012.2196285

38. Singh K, Bharatha A, Sa B, Adams OP, Majumder MAA (2019) Teaching anatomy using an active and engaging learning strategy. BMC Med Educ 19:149. https://doi.org/10.1186/ s12909-019-1590-2

39. Stowell JR, Bennett D (2010) Effects of online testing on student exam performance and test anxiety. J Educ Comput Res 42:161171. https://doi.org/10.2190/EC.42.2.b

40. Zilverschoon M, Vincken KL, Bleys RL (2017) The virtual dissecting room: creating highly detailed anatomy models for educational purposes. J Biomed Inform 65:58-75. https://doi.org/10. 1016/j.jbi.2016.11.005

41. Zorzal ER, Sousa M, Mendes D, dos Anjos RK, Medeiros D, Paulo SF et al (2019) Anatomy studio: a tool for virtual dissection through augmented 3D reconstruction. Comput Graph 85:74-84. https://doi.org/10.1016/j.cag.2019.09.006

Publisher's Note Springer Nature remains neutral with regard to jurisdictional claims in published maps and institutional affiliations. 